\title{
Simulations of a Circulating Fluidized Bed Chemical Looping Combustion System Utilizing Gaseous Fuel
}

\author{
K. Mahalatkar 1,2, J. Kuhlman',3, E.D. Huckaby ${ }^{3}$ and T. O'Brien ${ }^{3^{*}}$ \\ 1 West Virginia University, Dept. of Mechanical and Aerospace Engineering, Morgantown, WV, 26506 - USA \\ 2 ANSYS Inc., 3647 Collins Ferry Road Suite A, Morgantown, WV, 26505 - USA \\ 3 National Energy Technology Laboratory, 3610 Collins Ferry Road, Morgantown, WV, 26507 - USA \\ e-mail: kar982@gmail.com - john.kuhlman@mail.wvu.edu - e.david.huckaby@netl.doe.gov - thomas.obrien@netl.doe.gov \\ * Corresponding author
}

Résumé - Simulation de la combustion en boucle chimique d'une charge gazeuse dans un lit fluidisé circulant - Des études numériques de simulation des écoulements (CFD) ont été réalisées sur un lit fluidisé circulant opérant en combustion par boucle chimique (CLC) décrit dans la littérature (Abad et al., 2006 Fuel 85, 1174-1185). Si de nombreuses études expérimentales ont été conduites pour étudier le procédé CLC, les études concernant la simulation des écoulements par CFD de ce concept sont très limitées. Le système de combustion en boucle chimique simulé dans cette étude concerne la combustion d'une charge gazeuse (méthane). Un modèle 2-D à deux phases continues a été utilisé pour décrire les phases gaz et solide avec des sous-modèles détaillés pour décrire les forces d'interactions entre fluideparticule et particule-particule. Des modèles cinétiques globaux ont été intégrés pour décrire les réactions de combustion et de transformation du matériau transporteur d'oxygène. Les résultats obtenus par CFD ont été comparés aux concentrations expérimentales mesurées des différentes espèces chimiques à la sortie du réacteur, aux débits de circulation, à la distribution massique des solides dans les réacteurs, aux fuites et aux taux de dilution. Les simulations CFD instationnaires montrent globalement une concordance raisonnable avec les données expérimentales rapportées.

\begin{abstract}
Simulations of a Circulating Fluidized Bed Chemical Looping Combustion System Utilizing Gaseous Fuel - Numerical studies using Computational Fluid Dynamics (CFD) have been carried out for a complete circulating fluidized bed chemical looping combustor described in the literature (Abad et al., 2006 Fuel 85, 1174-1185). There have been extensive experimental studies in Chemical Looping Combustion (CLC), however CFD simulations of this concept are quite limited. The CLC experiments that were simulated used methane as fuel. A 2-D continuum model was used to describe both the gas and solid phases. Detailed sub-models to account for fluid-particle and particleparticle interaction forces were included. Global models of fuel and carrier chemistry were utilized. The results obtained from CFD were compared with experimental outlet species concentrations, solid circulation rates, solid mass distribution in the reactors, and leakage and dilution rates. The transient CFD simulations provided a reasonable match with the reported experimental data.
\end{abstract}




\section{NOTATION}

$b \quad$ Numerical parameter in the frictional stress model

$C_{\mathrm{CH}_{4}} \quad$ Concentration of methane $\left(\mathrm{kmol} / \mathrm{m}^{3}\right)$

$\mathrm{C}_{\mathrm{O}_{2}} \quad$ Concentration of oxygen $\left(\mathrm{kmol} / \mathrm{m}^{3}\right)$

$E \quad$ Activation energy for oxidation of $\mathrm{CH}_{4}(\mathrm{~kJ} / \mathrm{kmol})$

$\mathrm{Fr} \quad$ Numerical parameter in the frictional stress model $\left(\mathrm{N} / \mathrm{m}^{2}\right)$

$\overline{\bar{I}} \quad$ Unity tensor or matrix

$I_{2 D} \quad$ Second invariant of the strain tensor $\left(1 / \mathrm{s}^{2}\right)$

$k \quad$ Rate coefficient for the heterogeneous reaction between $\mathrm{Mn}_{3} \mathrm{O}_{4}$ and $\mathrm{O}_{2}(1 / \mathrm{s})$

$k_{\mathrm{CH}_{4}} \quad$ Preexponential coefficient for oxidation of $\mathrm{CH}_{4}$ $\left(\mathrm{kmol} / \mathrm{m}^{3}\right)^{-1} \mathrm{~s}^{-1} \mathrm{~K}$

$k_{\mathrm{O}_{2}} \quad$ Rate coefficient for the heterogeneous reaction between $\mathrm{MnO}$ and $\mathrm{O}_{2}(1 / \mathrm{s})$

$m \quad$ Numerical parameter in the frictional stress model

$m \quad$ Mass of the carrier $(\mathrm{kg})$

$m_{o x} \quad$ Mass of the carrier when completely oxidized $(\mathrm{kg})$

$m_{\text {red }} \quad$ Mass of the carrier when completely reduced $(\mathrm{kg})$

$\dot{m}_{\mathrm{CH}_{4}} \quad$ Rate of consumption of methane mass $(\mathrm{kg} / \mathrm{s})$

$\dot{m}_{\mathrm{O}_{2}} \quad$ Rate of consumption of oxygene mass $(\mathrm{kg} / \mathrm{s})$

$M W_{\mathrm{CH}_{4}} \quad$ Molecular weight of methane $(\mathrm{kg} / \mathrm{kmol})$

$M W_{\mathrm{O}_{2}} \quad$ Molecular weight of oxygen $(\mathrm{kg} / \mathrm{kmol})$

$M W_{\mathrm{Mn}_{3} \mathrm{O}_{4}}$ Molecular weight of $\mathrm{Mn}_{3} \mathrm{O}_{4}(\mathrm{~kg} / \mathrm{kmol})$

$M W_{\mathrm{MnO}}$ Molecular weight of $\mathrm{MnO}(\mathrm{kg} / \mathrm{kmol})$

$n \quad$ Numerical parameter in the frictional stress model; also moles of a species

$p \quad$ Numerical parameter in the frictional stress model

$p_{f} \quad$ Granular pressure $\left(\mathrm{N} / \mathrm{m}^{2}\right)$

$R \quad$ Gas constant $(\mathrm{kJ} / \mathrm{kmol} / \mathrm{K})$

$R_{\mathrm{O}} \quad$ Oxygen carrying capacity

$t \quad$ Time (s)

$T \quad$ Temperature (K)

$\vec{u}_{s} \quad$ Granular velocity $(\mathrm{m} / \mathrm{s})$

$X \quad$ Conversion of the carrier

$Y_{\mathrm{CH}_{4}} \quad$ Mass fraction of methane

$Y_{\mathrm{Mn}_{3} \mathrm{O}_{4}} \quad$ Mass fraction of $\mathrm{Mn}_{3} \mathrm{O}_{4}$

$Y_{\mathrm{MnO}} \quad$ Mass fraction of $\mathrm{MnO}$

\section{Greek Letter}

$\alpha_{s} \quad$ Solids volume fraction

$\alpha_{s, \max }^{*} \quad$ Numerical parameter in the frictional stress model, maximum solids packing

$\alpha_{s, \min }^{*} \quad$ Numerical parameter in the frictional stress model, minimum solids packing

$\varepsilon_{s} \quad$ Solids volume fraction

$\eta_{\mathrm{CC}} \quad$ Carbon capture efficiency

$\phi \quad$ Numerical parameter in the frictional stress model, angle of internal friction $\mu_{f} \quad$ Granular frictional viscosity $\left(\mathrm{N} \cdot \mathrm{s} / \mathrm{m}^{2}\right)$

$\rho_{\text {avg }} \quad$ Average density of metal oxide $\left(\mathrm{kg} / \mathrm{m}^{3}\right)$

$\overline{\bar{\tau}}_{\text {friction }}$ Granular stress tensor, frictional regime $\left(\mathrm{N} / \mathrm{m}^{2}\right)$

$v_{\mathrm{Mn}_{3} \mathrm{O}_{4}}$ Stoichiometric coefficient for $\mathrm{Mn}_{3} \mathrm{O}_{4}$

$v_{\mathrm{MnO}}$ Stoichiometric coefficient for $\mathrm{MnO}$

\section{Subscript}

$f \quad$ Frictional regime of the granular stress

ox Oxidation

red Reduction

$s \quad$ Solids (granular) phase

\section{INTRODUCTION}

Responsible carbon management will be required for the future utilization of fossil fuels for power generation. One technology that is showing tremendous potential for carbon capture is Chemical Looping Combustion (CLC). CLC involves combustion of fuels by heterogeneous chemical reactions with an oxygen carrier, usually a granular metal oxide, that is exchanged between two fluidized beds. The CLC process for power generation provides a sequestration ready $\mathrm{CO}_{2}$ stream without the need for using costly gas separation techniques. The net chemical reaction and energy release is identical to that of the conventional combustion of the fuel. The energy spent on solid circulation (the only energy cost of separation) is very small $(\sim 0.3 \%)$ in comparison with the total energy released (Lyngfelt et al., 2001).

CLC requires many unit operations involving gas-solid or granular flow. A CLC system consists of two reactors, a Fuel Reactor (FR) and an Air Reactor (AR). The FR is typically a bubbling or moving bed. The AR, usually a transport reactor, re-oxidizes the reduced carrier. At its exit the oxidized carrier is separated by a cyclone or an expansion region and returned to the FR. Thus the CLC system is, basically, a Circulating Fluidized Bed (CFB) where solid particles are circulated between the AR and FR.

To date only a very limited number of Computational Fluid Dynamics (CFD) simulations have been performed on full CFBs, due to their complex geometry, the rapid variations between flow regimes, and the large computational capacity required. Most CFD simulations of CFBs have limited themselves to the riser section (O'Brien and Syamlal, 1993; Guenther et al., 2002; Mao et al., 2004). Simulating a limited section of the CFB requires inputs to the numerical model that are difficult to specify in an accurate manner (such as the solids circulation rate). Simulating individual units of a CFB system can, therefore, limit the usefulness of CFD in a design study. Also, the advanced CFB systems that are being developed today (such as for CLC) will require the use of complex control systems to run them in an efficient manner. To design 
these control systems there is a need to develop mathematical models that can predict the behavior of the entire CFB. CFD could be used as a tool to develop these complex control models or it could even be directly coupled with the control system design software. Several simulations of a full Circulating Fluidized Bed have been reported (Samuelsberg and Hjertager, 1996; Mathiesen et al., 2000). However these two dimensional (2D) CFD simulations simplified the actual complex three dimensional (3D) geometry (e.g., cyclone and connecting pipes) into a 2D form and primarily focused on comparing with experimental results within the riser section. In most CFB systems the solids circulation rate is limited by narrow flow sections such as pipes, loop seals, etc., and, hence, there is a need to accurately represent these regions in a CFD simulation. In a CLC system, predicting the right solids circulation rates for an oxygen carrier is essential as it directly affects the amount of fuel that can be burned and the heat transfer between reactors. In the present study detailed mathematical models have been incorporated to describe the flow of solid particles both in the dense and dilute regimes so that an entire CFB system can be analyzed.

The design of a Chemical Looping Combustion system requires consideration of a number of important parameters, e.g.:

- combustion efficiency of the reactor (low unburned fuel in the FR outlet);

- carbon capture efficiency of the system (low leakage of fuel into the AR);

- solids circulation rate (enough oxygen and heat for combustion in FR);

- gas leakage between reactors (dilution of $\mathrm{CO}_{2}$ by $\mathrm{N}_{2}$ in the FR).

The use of CFD can help in estimating the performance of the reactor based on the above parameters without making unit-specific assumptions in the modeling procedure. The focus of the present study is on accurately predicting the performance of a complete experimental CLC system (Abad et al., 2006; Johansson et al., 2006), based on the two-compartment fluidized bed design. This is one of the few complete CLC experiments which is documented in detail in the published literature. Also, the geometry can easily be approximated as 2D since the depth is constant, with exception of a $3 \mathrm{D}$ expansion region for particle separation above the AR, the effect of which can be mimiced by a horizontal expansion in $2 \mathrm{D}$. The experimentalists provided detailed information on the concentrations of flue gases and solids circulation rates at several different reactor operating conditions. This provides extensive data which has been used to validate the CFD models described herein. These will be utilized in design studies of experimental CLC systems at the National Energy Technology Lab (NETL), Morgantown, West Virginia, USA.

\section{THE EXPERIMENTAL STUDIES}

The experiments of (Abad et al., 2006) are for hot flow conditions, using a manganese oxide carrier, supported on zirconium oxide, and burning natural gas. The AR fluidizing velocity is higher than the terminal velocity of the carrier particles and therefore carries the particles upwards into the top section, which is an expansion section, causing particle disengagement. In the experiments, the particle separator is actually a gradual depth expansion (perpendicular to the

TABLE 1

Simulated CLC Properties (Abad et al., 2006)

\begin{tabular}{l|l}
\hline Width of FR (mm) & 25 \\
\hline Width of AR (mm) & 40 \\
\hline Depth of reactor sections (mm) & 25 \\
\hline Width of downcomer (mm) & 12 \\
\hline Fluidizing gas composition in FR & $100 \% \mathrm{CH}_{4}$ \\
\hline Fluidizing gas composition in AR & $100 \%$ Air \\
\hline Average diameter of particles (microns) & 150 \\
\hline Average density of particles $\left(\mathrm{kg} / \mathrm{m}^{3}\right)$ & 2260 \\
\hline Range of FR flow rates $\left(\mathrm{m}^{3} / \mathrm{s}\right)$ & $2.5 \times 10^{-6}$ to $7.5 \times 10^{-6}$ \\
\hline Range of AR flow rates $\left(\mathrm{m}^{3} / \mathrm{s}\right)$ & $66.7 \times 10^{-6}$ to $91.7 \times 10^{-6}$ \\
\hline Mass of metal oxide particle bed $(\mathrm{g})$ & 300 \\
\hline
\end{tabular}

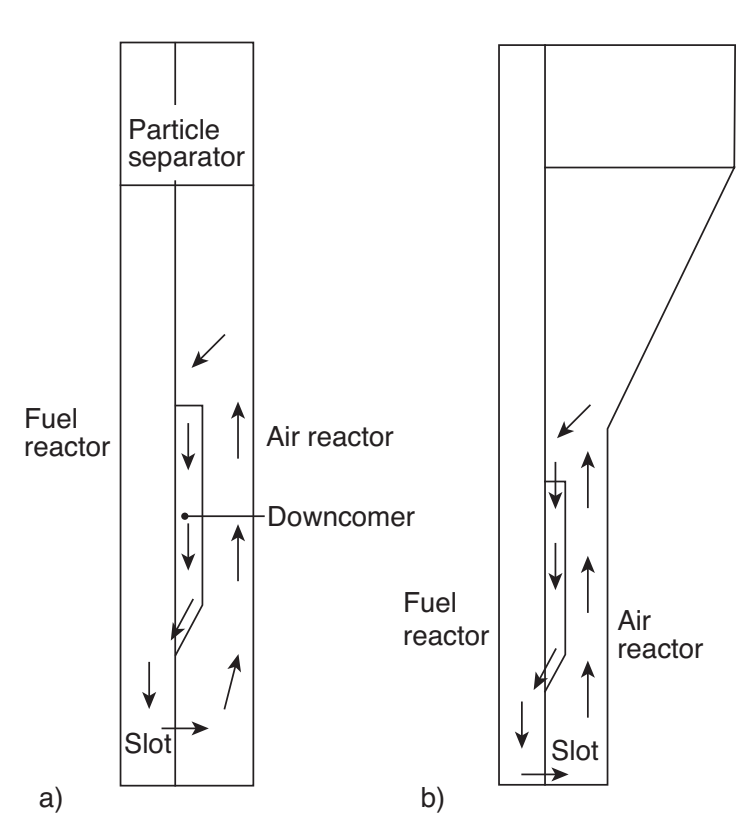

a)

b)

Figure 1

a) Actual $3 \mathrm{D}$ experimental geometry (front view);

b) 2D simulated geometry. 
plane of the 2D simulation) that begins just above the downcomer section (Fig. la). In the present case the geometry has been modified such that the expansion is areal in the 2D plane being simulated (Fig. 1b). Note that the actual and simulated expansion regions have the same cross-sectional outlet areas. Since this expansion occurs above the circulating bed, it is thought to be unlikely to affect the solution significantly. Table 1 provides the details of geometry and fluidization conditions.

\section{THE CFD MODEL}

The present simulations were performed invoking the interpenetrating fluid representation of dense multiphase flow using the Fluent code ${ }^{\circledR}$. The granular phase was represented as a continuum whose dynamics is governed by Navier-Stokes like equations, coupled to the N-S equations describing the fluid flow. Detailed sub-models to account for fluid-particle and particle-particle interaction forces have been included. Chemical reactions are included and heat transfer is fully accounted for. The detailed equations are described in Mahalatkar et al. (2010) and in Ansys-Fluent (2006).

The granular multiphase flows display complex nonlinear rheology; the physics of the granular flow changes considerably depending on the packing and deformation rate. The granular flows are usually classified into three regimes (Gidaspow, 1994; Langroudi et al., 2010a, b):

- kinetic regime,

- transitional regime and,

- frictional regime.

The kinetic regime is strictly valid at low solids volume fraction, where the mean free path of the grains is large in comparison with their diameter. However, it seems to be accurate for much higher concentrations. At very high concentrations ( $\alpha_{s}>0.5$, where $\alpha_{s}$ is the solids volume fraction), the frictional regime is dominant. The particles in this case are closely packed and in enduring contact. There are large dissipative frictional forces acting between the particles. As the name implies, the transitional regime occurs at intermediate concentrations where energy is dissipated both through inelastic particle collisions and enduring frictional contact.

A good rheological model has to account for all the above regimes accurately. This is difficult as the operative physics in these regimes are considerably different from one another and yet there is considerable overlap between regimes. In the present analysis, the intermediate overlap region is described by the sum of the rheological models in the kinetic-collision and the frictional regimes (Johnson and Jackson, 1987). This assumption appears reasonable so long as the quantitative effects of the kinetic regime tend to zero in the frictional regime and vice versa. The detailed equations for the rheological model in the kinetic regime that was used in the present study have been described in Mahalatkar et al. (2010) and Ansys-Fluent (2006). When the solids fraction is close to the dense packing limit, enduring frictional interactions between particles becomes important. Therefore, for $\alpha_{s}>0.5$, an additional frictional term is added to solid stress:

$$
\overline{\bar{\tau}}_{\text {friction }}=-p_{f} \overline{\bar{I}}+\mu_{f}\left(\nabla \vec{u}_{s}+\left(\nabla \overrightarrow{u_{s}}\right)^{T}\right)
$$

where $p_{f}$ is the pressure acting between solid particles and $\mu_{f}$ is the frictional viscosity which accounts for the shear stresses generated due to frictional flow.

Generally, viscoplastic models developed from plasticity theory are used for describing the frictional stress-strain relationship. For the Abad experiments, it was reported that the frictional flow in the downcomer causes it to pack with solids and, thus, limit the solids circulation rates. Therefore, to match experimental results this phenomenon must be accurately predicted. The frictional model used was developed by (Langroudi et al., 2010b, a). The frictional viscosity is given by:

$\mu_{f}=\left\{\begin{array}{cl}\sqrt{2} p_{f}\left(\frac{\sin \phi+b \cos \phi \times\left(I_{2 D}\right)^{m / 2}}{\sqrt{I_{2 D}}}\right) & \text { if } \alpha_{s}>\alpha_{s, \text { min }}^{*} \\ 0 & \text { if } \alpha_{s} \leq \alpha_{s, \text { min }}^{*}\end{array}\right.$

where the values used are $b=0.13, m=0.72$ and $\phi=30^{\circ}$, the angle of internal friction. Also, $I_{2 D}$ is the second invariant of the strain tensor. The frictional pressure is the (Johnson and Jackson, 1987) representation:

$$
p_{f}=F r \frac{\left(\alpha_{s}-\alpha_{s, \min }^{*}\right)^{n}}{\left(\alpha_{s, \max }^{*}-\alpha_{s}\right)^{p}}
$$

where the parameter values used are: $F r=5.0, n=2, p=3$, $\alpha_{s, \max }^{*}=0.63$ and $\alpha_{s, \min }^{*}=0.5$.

\section{THE REACTION SCHEME AND RATES}

The following global reaction mechanism was used to describe the oxidation of methane in the FR and the AR and the regeneration of the carrier in the AR:

Reduction Reaction

$$
4 \mathrm{Mn}_{3} \mathrm{O}_{4}+\mathrm{CH}_{4} \rightarrow 12 \mathrm{MnO}+\mathrm{CO}_{2}+2 \mathrm{H}_{2} \mathrm{O}
$$

Oxidation Reactions

$$
\begin{gathered}
12 \mathrm{MnO}+2 \mathrm{O}_{4} \rightarrow 4 \mathrm{Mn}_{3} \mathrm{O}_{4} \\
\mathrm{CH}_{4}+2 \mathrm{O}_{4} \rightarrow \mathrm{CO}_{2}+2 \mathrm{H}_{2} \mathrm{O}
\end{gathered}
$$


Son and Kim (2006) suggest that the uniform reaction model can best represent the heterogeneous chemical reactions of the metal oxide carriers used in a CLC system. For this reaction model:

$$
\frac{d X}{d t}=k(1-X)
$$

where $X=\left(m-m_{r e d}\right) /\left(m_{o x}-m_{r e d}\right)$ is the conversion. Here $m_{o x}$ is the completely oxidized mass, i.e., the molecular mass of $\mathrm{Mn}_{3} \mathrm{O}_{4}$, and $m_{\text {red }}$ is the reduced form, MnO. Alternatively, Mattisson et al. (2005) suggested that the grain model, controlled by the chemical reactions, is most suitable, implying that $d X / d t=k(1-X)^{2 / 3}$. However, in the present study, the uniform reaction model was used (Son and Kim, 2006). The rate coefficient $k$ was represented in standard Arrhenius form, $k=k_{0} e^{-E / R T}$. Adanez et al. (2004) used thermogravimetric analysis to determine the heterogeneous reaction rates for manganese oxide particles with the same type and percentage of support material as those used in the present case. Based on their studies, the following constants for the reduction reaction have been extracted from their TGA data: $k_{0}=2943.515 \mathrm{~s}^{-1}$ and $\mathrm{E}=104628.4 \mathrm{~J} /(\mathrm{K} \cdot \mathrm{mol})$.

Differentiating Equation (6),

$$
\frac{d X}{d t}=\frac{1}{m_{o x}-m_{\text {red }}} \frac{d m}{d t}=\frac{1}{R_{o} m_{o x}} \frac{d m}{d t}
$$

where $R_{o}=\left(m_{o x}-m_{r e d}\right) / m_{o x}$. All the loss in mass of metal oxide is because of loss of oxygen, therefore, $d m=d m_{\mathrm{O}_{2}}=$ $M W_{\mathrm{O}_{2}} \times d n_{\mathrm{O}_{2}}$, where $M W_{\mathrm{O}_{2}}$ is the molecular weight of $\mathrm{O}_{2}$. Further it can be shown that the rate of consumption of methane $\left(\mathrm{kg} /\left(\mathrm{m}^{3} \cdot \mathrm{s}\right)\right)$ is given by:

$$
\begin{aligned}
& \dot{m}_{\mathrm{CH}_{4}}=\frac{k R_{o}}{2 M W_{\mathrm{O}_{2}}}(1-X) \rho_{\text {avg }} \varepsilon_{s} \\
& \left(Y_{\mathrm{Mn}_{3} \mathrm{O}_{4}}+Y_{\mathrm{MnO}} \times \frac{v_{\mathrm{Mn}_{3} \mathrm{O}_{4}} M W_{\mathrm{Mn}_{3} \mathrm{O}_{4}}}{v_{\mathrm{MnO}} M W_{\mathrm{MnO}}}\right) \frac{Y_{\mathrm{CH}_{4}}}{Y_{\mathrm{CH}_{4}-T G A}} M W_{\mathrm{CH}_{4}}
\end{aligned}
$$

where $Y_{\mathrm{CH}_{4}-T G A}$ is the methane mass fraction in the TGA experiments during the reducing phase of the experiment. These rates are scaled linearly for other concentration values. The TGA concentration of $\mathrm{CH}_{4}$ was $70 \%\left(70 \% \mathrm{CH}_{4}\right.$ and $30 \% \mathrm{H}_{2} \mathrm{O}$ ) or $Y_{\mathrm{CH}_{4}-T G A}=0.675$.

For the carrier oxidation reaction, the rate is fast and almost constant within the temperature range of the present experiments (Adanez et al., 2004). The coefficient $k$ is estimated to be 0.1 . The reaction rate for the oxidation reaction $\left(\mathrm{kg} /\left(\mathrm{m}^{3} \cdot \mathrm{s}\right)\right)$ can be shown to be:

$$
\begin{aligned}
& \dot{m}_{\mathrm{O}_{2}}=\frac{k R_{o}}{M W_{\mathrm{O}_{2}}}(X) \rho_{\text {avg }} \varepsilon_{s} \times \\
& \left(Y_{\mathrm{Mn}_{3} \mathrm{O}_{4}}+Y_{\mathrm{MnO}} \times \frac{v_{\mathrm{Mn}_{3} \mathrm{O}_{4}} M W_{\mathrm{Mn}_{3} \mathrm{O}_{4}}}{v_{\mathrm{MnO}} M W_{\mathrm{MnO}}}\right) \frac{Y_{\mathrm{O}_{2}}}{Y_{\mathrm{O}_{2}-T G A}} M W_{\mathrm{O}_{2}}
\end{aligned}
$$

where $Y_{\mathrm{O}_{2}-T G A}$ is the oxygen mass fraction in the TGA experiments during the oxidizing phase of the experiment. Since the experiments were carried out using air, $Y_{\mathrm{O}_{2}-T G A}=0.23$.

A global reaction rate reported for the homogeneous oxidation of methane by oxygen in systems utilizing coal and biomass as fuel was used to describe its consumption in the AR:

$$
\dot{m}_{\mathrm{CH}_{4}}=k_{\mathrm{CH}_{4}} e^{(-E / R T)} T^{-1}\left(C_{\mathrm{CH}_{4}}\right)\left(C_{\mathrm{O}_{2}}\right)
$$

where $k_{\mathrm{CH}_{4}}=3.552 \times 10^{14}\left(\mathrm{kmol} / \mathrm{m}^{3}\right)^{-1} \mathrm{~s}^{-1} \mathrm{~K}$ and $E / R=15700 \mathrm{~K}$ (de Souza-Santos, 2004).

\section{THE INITIAL AND BOUNDARY CONDITIONS}

The total mass of solids in the system was 300 grams (Tab. 1). The density of the fully oxidized carrier particles was $2260 \mathrm{~kg} / \mathrm{m}^{3}$. An initial bed height of $136 \mathrm{~mm}$ was determined from the geometry of the reactor, assuming a packing fraction of 0.6. For the experiments, the entire reactor was placed in an oven. To simulate this effect the system was assumed to be isother$\mathrm{mal}$; the temperature was fixed at the temperature of the experiments $\left(800-950^{\circ} \mathrm{C}\right)$ and the energy equations were not solved. The inlet gases were also assumed to be at the operating temperature of the reactor.

\section{NUMERICAL PARAMETERS}

Three different grid sizes (coarse, medium and fine) were used in the present study to establish grid independence. The spatial discretization used for the volume fraction equations was the quadratic upwind interpolation scheme (QUICK); second order upwind discretization was used for all other equations. The temporal discretization scheme in all cases was first order implicit. The CFD domain for the geometry of the FR used in the simulation is shown in Figure 2. The mesh used quadrilateral cells. The cell counts and time steps used are presented in Table 2. Obviously, a larger computational time was required for the finer mesh, mainly due to the smaller time step; small time steps were essential for numerical stability of the solution. The results presented here used the medium size mesh, unless stated otherwise, since this showed reasonable resolution. Table 2 also shows the number of cells used to resolve the width of the downcomer and slot, which limit the transfer of solids between the AR and FR. The flow in these regions has to be well resolved to obtain accurate solid circulation rates.

\section{RESULTS}

Figure 3a shows the volume fraction of the gas phase throughout the reactor at one representative instant (a snapshot) at an operating temperature of $1123 \mathrm{~K}$. The formation and rise of 


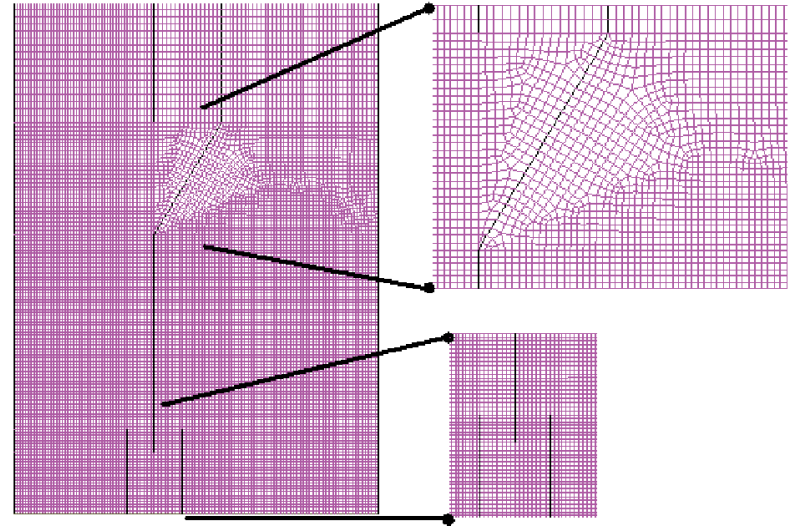

a)

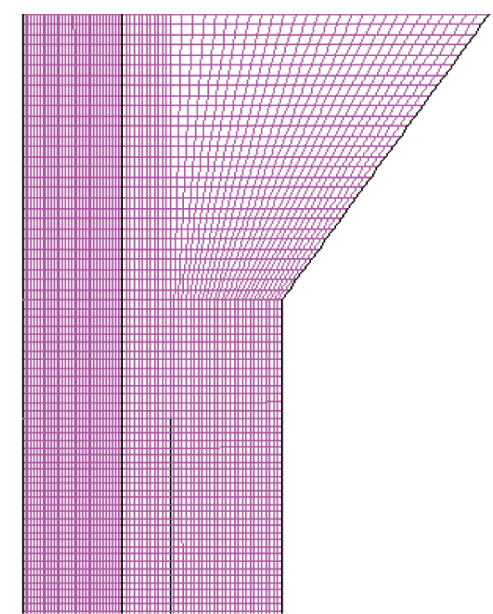

b)

Figure 2

Fine mesh used in the numerical study. a) Mesh at the bottom of CFD domain; b) mesh at the top of the CFD domain.

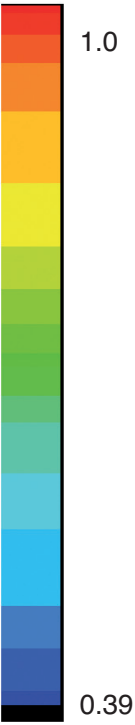

a)

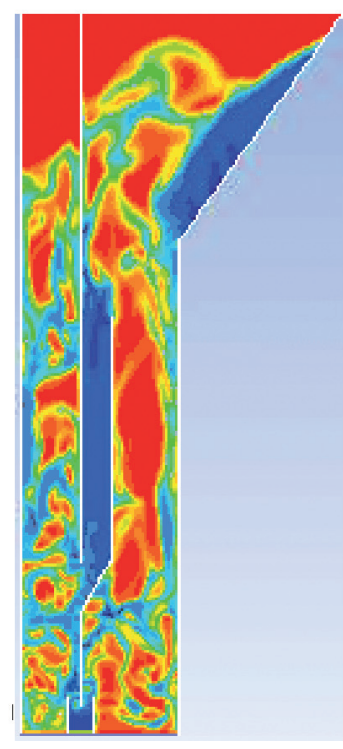

b)

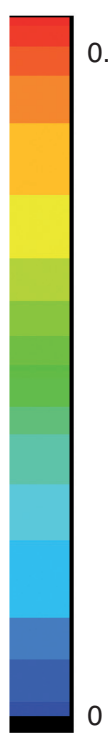

b)
0.5

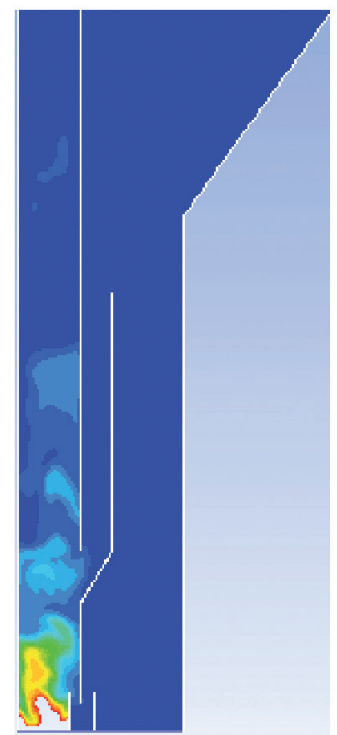

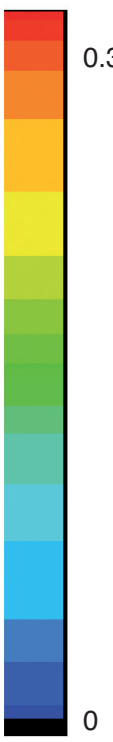

c)
0.33

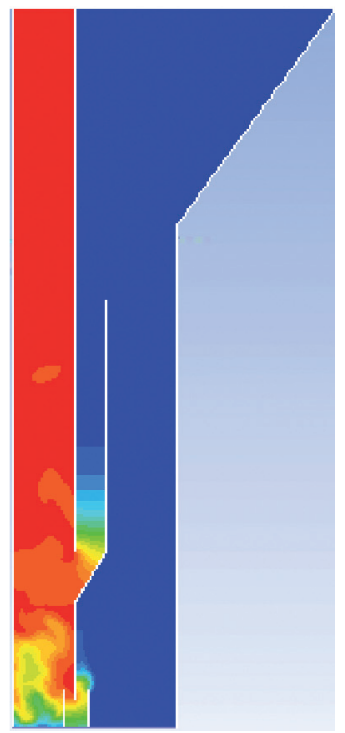

Figure 3

Instantaneous gas volume fraction and gas species mole fraction contours $\left(T=1123 \mathrm{~K}\right.$, FR flow rate $=7.5 \times 10^{-6} \mathrm{~m}^{3} / \mathrm{s}$ and AR flow rate $=83 \times 10^{-6} \mathrm{~m}^{3} / \mathrm{s}$ ). a) Gas volume frac.; b) $\mathrm{CH}_{4}$; c) $\mathrm{CO}_{2}$.

TABLE 2

Numerical parameters for the simulations

\begin{tabular}{l|c|c|c}
\hline & $\begin{array}{c}\text { Coarse } \\
\text { mesh }\end{array}$ & $\begin{array}{c}\text { Medium } \\
\text { mesh }\end{array}$ & $\begin{array}{c}\text { Fine } \\
\text { mesh }\end{array}$ \\
\hline Number of cells & 8822 & 17562 & 33745 \\
\hline Number of cells to resolve slot width & 8 & 12 & 20 \\
\hline $\begin{array}{l}\text { Number of cells to resolve } \\
\text { downcomer width }\end{array}$ & 6 & 10 & 15 \\
\hline Time step (s) & $2 \times 10^{-4}$ & $1 \times 10^{-4}$ & $2.5 \times 10^{-5}$ \\
\hline
\end{tabular}

bubbles can be clearly seen in the FR on the left. The bubbles are "fast" as expected for a bed material of this size and density, so that a "cloud" of gas rises with the bubbles (Collins, 1965). The downcomer connecting the two reactors is densely packed. This packing is associated with a dense frictional flow regime and limits the solid circulation rate. This was also observed in the cold flow experimental studies of the same system by (Kronberger et al., 2004).

Figure 3 also shows simultaneous snapshots of the computed mole fractions of two gas species, $\mathrm{CH}_{4}$ and $\mathrm{CO}_{2}$. Figure $3 \mathrm{~b}$ shows the rapid consumption of $\mathrm{CH}_{4}$ as it enters the FR. 


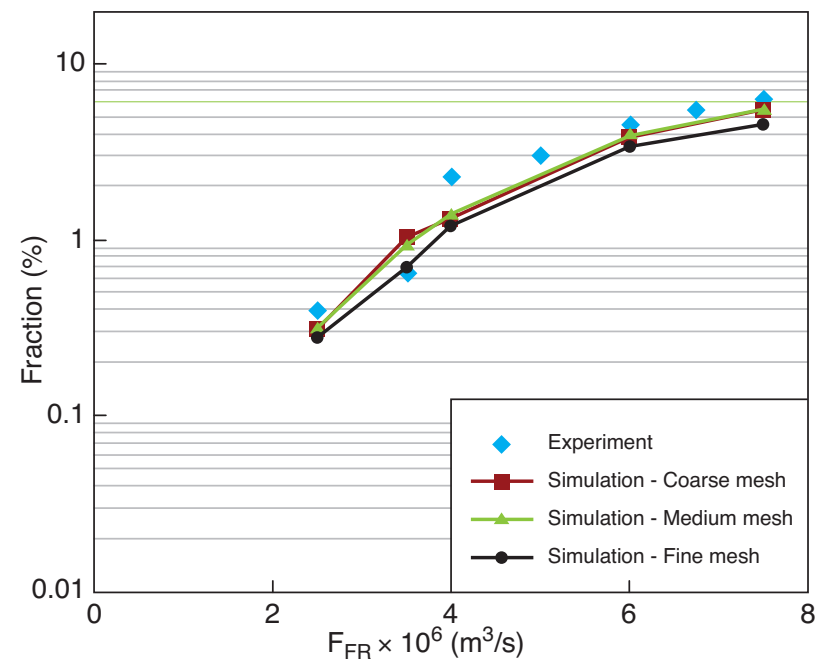

Figure 4

Variation in outlet $\mathrm{CH}_{4}$ fraction $\left(\mathrm{X}_{\mathrm{CH}_{4}} /\left(\mathrm{X}_{\mathrm{CH}_{4}}+X_{\mathrm{CO}}+X_{\mathrm{CO}_{2}}\right)\right)$ with FR flow rate $\left(2.5 \times 10^{-6}\right.$ to $\left.7.5 \times 10^{-6} \mathrm{~m}^{3} / \mathrm{s}\right)$.

AR flow rate $=83 \times 10^{-6} \mathrm{~m}^{3} / \mathrm{s}$.

Locally, a higher concentration of $\mathrm{CH}_{4}$ is observable in the bubble regions, (cf. Fig. 3a), indicating that some amount of fuel bypasses the bed through the bubbles, reducing gas-solid reactions. Figure $3 \mathrm{c}$ shows the mole fraction of $\mathrm{CO}_{2}$. This is low at the inlet region but increases with bed height as the $\mathrm{CH}_{4}$ reacts with the metal oxide. Some leakage of $\mathrm{CO}_{2}$ into the AR can be observed. It is desirable that the CLC reactor consumes all the supplied fuel, maintaining a high combustion efficiency. This can be achieved by having a larger solids inventory in the system; a deeper bed will decrease gas bypassing. However, this will result in a higher power requirement to fluidize the bed. Therefore, there is a need to achieve an optimum level of solid inventory.

To be useful in design, a CFD model should be able to accurately estimate the methane consumption over a range of solid inventory and fuel and air flow rates. Figure 4 shows the comparison of the variation of outlet $\mathrm{CH}_{4}$ mole fraction with change in the FR flow rate at $1223 \mathrm{~K}$. At lower flow rates the time required for the fuel to flow through the FR bed is longer and, hence, it has more time to react with the metal oxides resulting in a lower outlet concentration of the fuel. Also, the bubble size and frequency are lower at lower flow rates reducing the amount of fuel escaping through the bubbles. The variation in $\mathrm{CH}_{4}$ concentration is captured reasonably well by the simulations for the entire range of flow rates tested. Note that these results indicate fuel conversion levels between $94 \%$ to over $99 \%$. The differences between the calculated outlet methane concentrations and those reported experimentally are attributed to three main reasons:

- the method of preparation for the metal oxide used by Abad et al. (2006) was different from that of Adanez et al.
(2004). This would result in differences in porosity and available particle surface area of the metal oxide which can cause differences in the reaction rates;

- the chemistry model used is a curve fit to available experimental data from a thermogravimetric analyzer (TGA). The TGA experiments were carried out at a single concentration of methane by flooding the reaction chamber with excess amount of gases (Adanez et al., 2004). In the actual experimental system, the methane concentration will vary from close to $0 \%$ to $100 \%$. A linear scaling in reaction rates has been assumed with respect to the concentration of methane, which may not necessarily be accurate;

- errors in the simulation, such as errors in the calculated bubble size or frequency, can cause the outlet concentration to vary. As discussed above, "fast" bubbles allow the leakage of gases through the bed (Collins, 1965). However, detailed simulations (Hulme et al., 2005; Chandrasekaran et al., 2005) have shown that the multiphase fluid mechanics can be reasonably predicted by using mathematical models that are similar to those used in the present study.

Figure 5 shows the variation of outlet $\mathrm{CH}_{4}$ concentration with change in operating temperature (top scale) as well as with changes in air flow rates (bottom scale). Once again the CFD model predicts trends reasonably well. At low operating temperatures, the reactions are slower, resulting in higher fuel concentrations at the exit. However, at the highest temperature of $1223 \mathrm{~K}$, the outlet fuel fraction is less than $1 \%$. The outlet

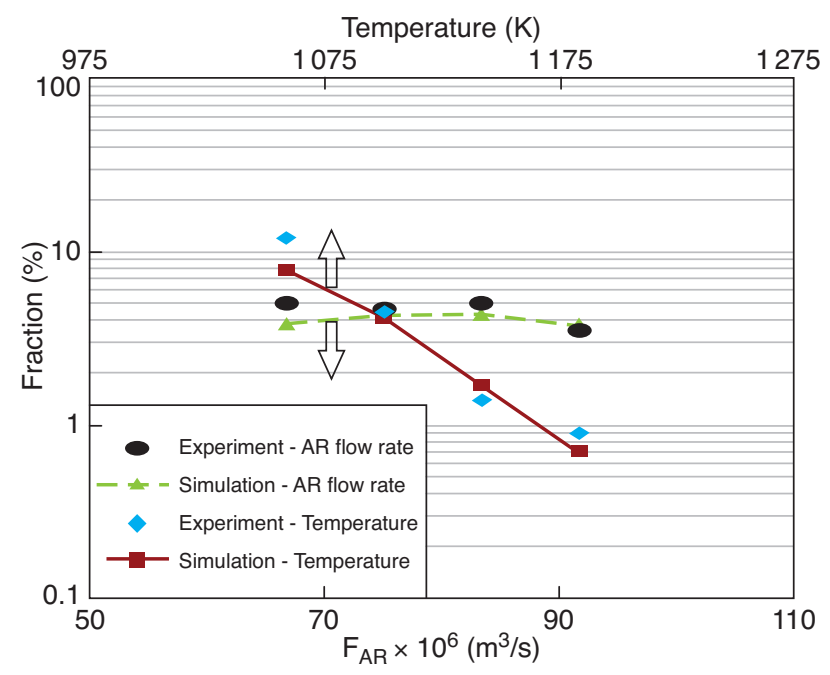

Figure 5

Variation in outlet $\mathrm{CH}_{4}$ fraction $\left(\mathrm{X}_{\mathrm{CH}_{4}} /\left(\mathrm{X}_{\mathrm{CH}_{4}}+X_{\mathrm{CO}}+X_{\mathrm{CO}_{2}}\right)\right)$ with operating temperature from $1073 \mathrm{~K}$ to $1223 \mathrm{~K}$ (FR flow rate $=5.8 \times 10^{-6} \mathrm{~m}^{3} / \mathrm{s}$ and AR flow rate $=83 \times 10^{-6} \mathrm{~m}^{3} / \mathrm{s}$, top scale) and change in AR flow rate from $66.7 \times 10^{-6}$ to $91.7 \times$ $10^{-6} \mathrm{~m}^{3} / \mathrm{s}$ (FR flow rate $=5.8 \times 10^{-6} \mathrm{~m}^{3} / \mathrm{s}$ and operating temperature $=1123 \mathrm{~K}$, bottom scale). 


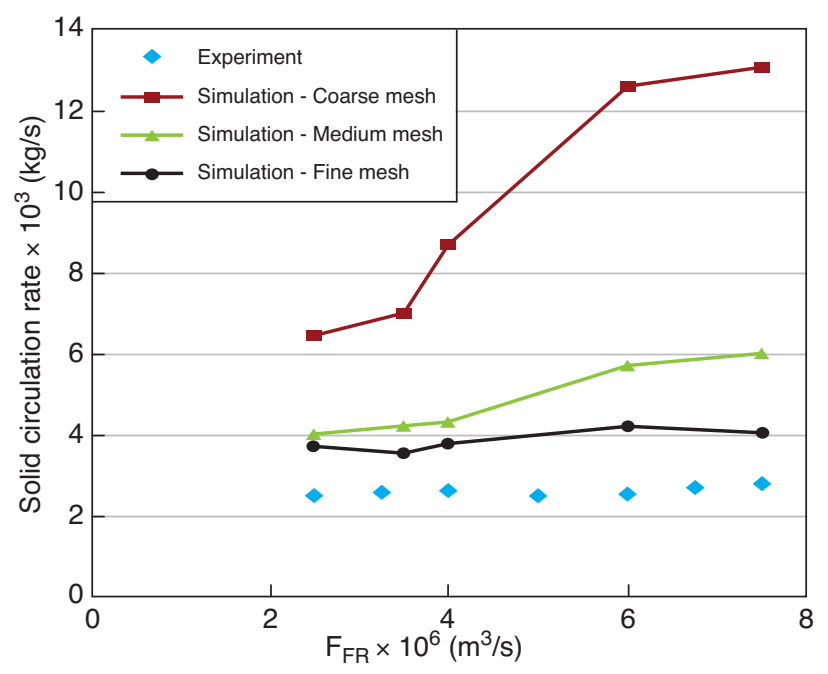

Figure 6

Variation in solid circulation rate $\left(\mathrm{kg} / \mathrm{s} \times 10^{3}\right)$ with FR flow rate $\left(2.5 \times 10^{-6}\right.$ to $\left.7.5 \times 10^{-6} \mathrm{~m}^{3} / \mathrm{s}\right)$. AR flow rate $=83 \times 10^{-6} \mathrm{~m}^{3} / \mathrm{s}$.

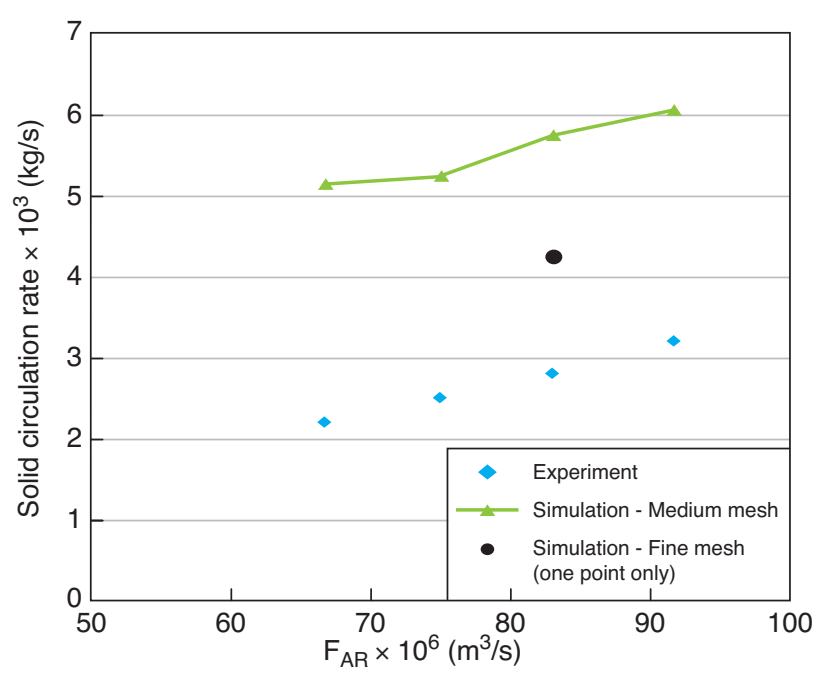

Figure 7

Variation in solid circulation rate $\left(\mathrm{kg} / \mathrm{s} \times 10^{3}\right)$ with AR flow rate $\left(66.7 \times 10^{-6}\right.$ to $\left.91.7 \times 10^{-6} \mathrm{~m}^{3} / \mathrm{s}\right)$. FR flow rate $=5.8 \times 10^{-6} \mathrm{~m}^{3} / \mathrm{s}$. fuel fraction does not vary significantly with change in the air flow rate. This is primarily because the solids circulation rate, as well the solid mass in the FR, do not change significantly. The reasons for this are discussed later.

Figure 6 shows the variation in solid circulation rate with change in the fuel flow rate. Predicting the solid circulation rate accurately is important as it determines the amount of oxygen supplied for burning the fuel as well as the energy transfer between the exothermic AR and the endothermic FR. The solids circulation is the primary means of energy transfer between the AR and FR, although this is irrelevant in these constant temperature experiments and simulations. The solids are observed to pack in the downcomer (Fig. 3a). The frictional energy dissipation in the downcomer of this CLC system is the primary controlling mechanism of the solids circulation rate. This is verified by running the simulations without any frictional stresses (i.e., excluding Eq. 1). It was found that without frictional stresses the circulation rates increased by a factor of $\sim 100$. The circulation rate is measured at the downcomer inlet which has the smallest oscillations in mass flux. From Figure 6 it is observed that the coarse mesh computation predicts a significantly larger flow rate than does the fine mesh. The difference can be attributed to numerical diffusion; a coarse mesh has higher numerical diffusion of the solid phases resulting in lower solids volume fraction in comparison with the finer mesh. A lower solid volume fraction will result in lower frictional stresses. This allows the solid circulation rates to be higher. From Figure 6 it can be observed that grid refinement results in more accurate prediction of solid circulation rates. Both the medium and fine mesh predict a slight increase in the solid circulation rates with an increase in fuel flow, as observed in experiments. The simulations also capture the slight increase in the solid circulation rates with increase in air flow (Fig. 7), although again the predicted solid circulation rates are higher than experimental values.

The differences between simulated and experimental solids flow rates can be attributed to a variety of causes, which will have to be further explored, including:

- in the present simulations, models based on plasticity theory have been used to determine the frictional stresses of the solids. Since frictional flow is extremely complex, this provides only an approximate representation of the flow physics;

- the viscoplastic model developed by Langroudi et al. (2009a, b) uses empirical coefficients ( $b$ and $m$ in Eq. 2) that have to be found from experiments as in a Couette type shear cell. This empirical data for the particles in the experimental study of Abad et al. is not available. Hence, values suggested in Langroudi et al. for related types of particles have been used;

- the experimental solid circulation rates were calculated indirectly from the transient increase in oxygen concentration after stopping the combustion test. This indirect method for measuring solid circulation rates is likely to introduce some error.

Another important parameter is the distribution of the solids between the fuel and air reactors. The amount of solids mass in the FR will directly affect the amount of methane burned there and, hence, it has to be predicted accurately. Table 3 shows the 
experimental and predicted mass in the two reactors. These values are extracted from the simulations using two different methods:

- the pressure drop across the reactor (Mass $=\Delta P \times$ Area $/ g$ ) and;

- direct integration (summation) of solid mass in all cells.

The calculated variation in solids inventory in the fuel and air reactors with changes in the fluidizing velocity is less than $2 \%$. This is similar to that observed in the experiments where the solids inventory remained, more or less, constant for the different cases. The computed mass in the FR was $11 \%$ less than the experimentally observed value (105 grams versus 94 grams, Tab. 3). The experimentally observed mass in the AR was 110 grams and the computed mass using pressure difference was 117 grams resulting in an error of 7\% (Tab. 3). The computed AR mass found using pressure difference is significantly different from that obtained by direct integration of solid mass in the reactors (117 grams versus 156 grams). This is attributed to the fact that the pressure difference does not account for the mass of solid particles deposited on the inclined walls of the particle separator, as they do not contribute to the pressure difference. Also, the affect of particle acceleration is not accounted for. However, the main reason for the differences between the simulations and experimental results is attributed to modeling assumptions such as the drag law, stress-strain relationships, packing limit, etc. For example, in the simulations the packing limit was assumed to be 0.63 ; however, the exact value is unknown. A higher/lower packing limit in the downcomer would change the solid mass distribution in the reactors.

TABLE 3

Mass of metal oxides

\begin{tabular}{l|c|c|c}
\hline & $\begin{array}{c}\text { Experimental } \\
\text { (pressure drop) }\end{array}$ & $\begin{array}{c}\text { CFD simulations } \\
\text { (pressure drop) }\end{array}$ & $\begin{array}{c}\text { CFD simulations } \\
\text { (direct integration) }\end{array}$ \\
\hline Solid mass in FR (g) & 105 & 94 & 97 \\
\hline Solid mass in AR (g) & 110 & 117 & 156 \\
\hline
\end{tabular}

Leakage between the AR and the FR is undesirable in a chemical looping system as it either causes $\mathrm{CO}_{2}$ to be released to the atmosphere (for leakage from the FR to the $\mathrm{AR}$ ) or dilutes the concentrated $\mathrm{CO}_{2}$ stream at the exit of the FR (for leakage from the AR to the FR). Neither occurrence is absolutely critical to the operation of a CLC system as, according to US-DOE guidelines, only $90 \%$ capture is required or, conversely, small amounts of $\mathrm{N}_{2}$ can be tolerated in the $\mathrm{CO}_{2}$ compression process. However, accurate prediction of this affect by the computational model is desirable.

Abad et al. (2006) define "leakage" as the fraction of gas flow from the FR to the AR and "dilution" as the fraction gas flow from the AR to the FR. Both are defined with respect to

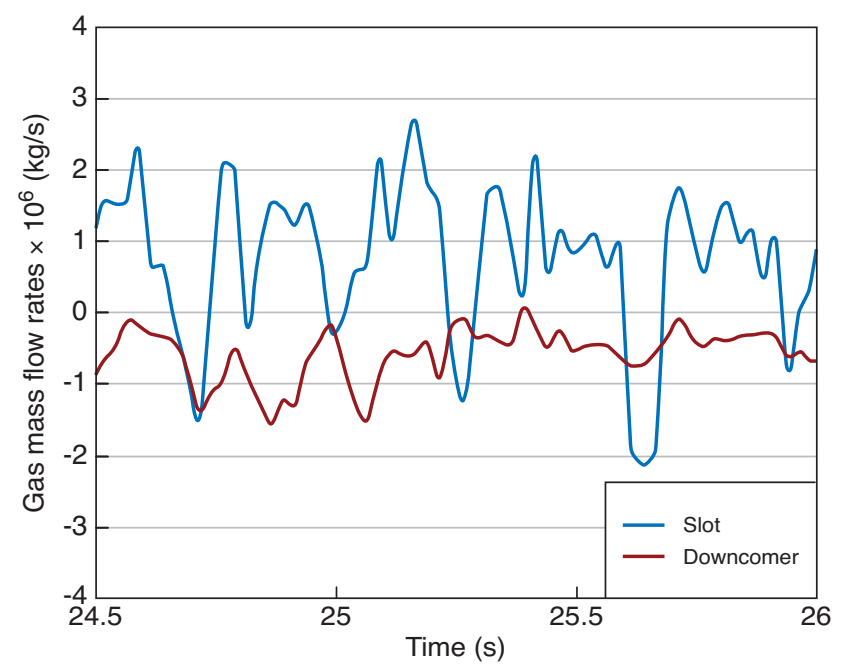

Figure 8

Predicted gas flow rates $\left(\mathrm{kg} / \mathrm{s} \times 10^{6}\right)$ through the slot and downcomer. AR flow rate is $83.0 \times 10^{-6} \mathrm{~m}^{3} / \mathrm{s}$. FR flow rate is $7.5 \times 10^{-6} \mathrm{~m}^{3} / \mathrm{s}$. Positive mass flow rates indicate flow from the FR to the AR; negative values indicate flow from the AR to the FR.

the incoming fuel flow, $F_{i n, F R}: L=F_{L} / F_{i n, F R}$, and $D=F_{D} / F_{i n, F R}$, where $F_{L}$ is the flow of gas from the FR to the AR and $F_{D}$ is the flow in the other direction. In the simulations, the leakage was calculated from the $\mathrm{CO}_{2}$ concentration at the exit of the $\mathrm{AR}$ and the dilution from the $\mathrm{N}_{2}$ concentration at the exit of the FR, as in the experimental study (Johansson et al., 2006).

Leakage and dilution occurs through both the slot and the downcomer. Figure 8 shows the gas mass flow rates at the downcomer inlet (on the AR side) and the slot connecting the FR and AR. It is observed that the gas flow through both downcomer and slot is the same order of magnitude. In the downcomer, the flow of gases is primarily from the AR to FR. This is despite the presence of a large adverse pressure gradient trying to push the gases from the FR to AR. The packing of the downcomer provides high resistance to the gas flow and, hence, prevents such a reverse flow of gas. However, the flow of solid particles causes a significant amount of gas to be dragged from the AR into the FR via the downcomer. In the slot, the gas flow is primarily from the FR to the AR. The gas pressure is on average higher on the FR side. This gas flow assists the transport of particles between reactors. The pressure oscillations occur due to the formation and rise of bubbles; this can cause a temporary reverse flow of gas from the AR to FR, leading to dilution.

Figure 9 shows the computed leakage and dilution with change in the fuel flow rates. The predicted values are between 3 and 10\%. Abad et al. (2006) report the experimental leakage and dilution of 3 to $30 \%$. In general, the gas 


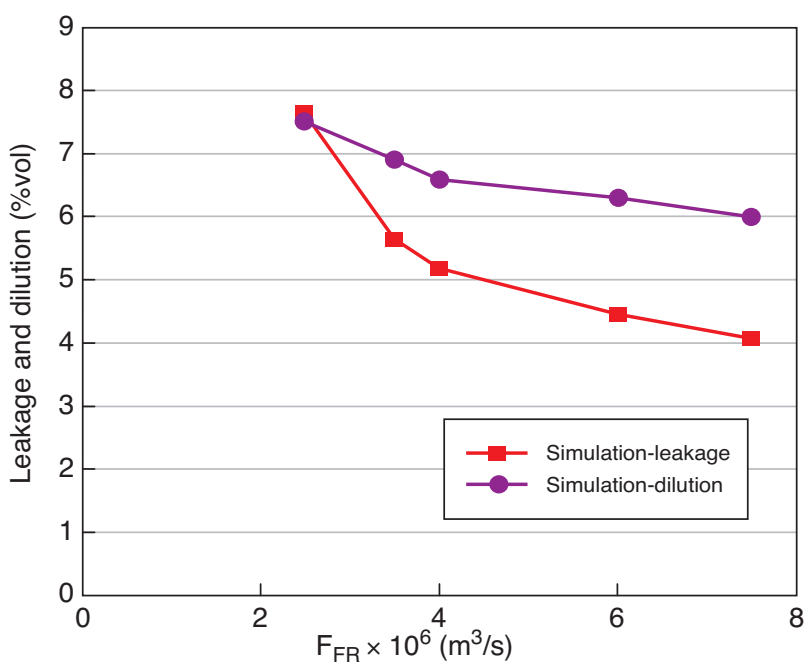

Figure 9

Variation in leakage and dilution (\%vol) with FR flow rates $\left(2.5 \times 10^{-6}\right.$ to $\left.7.5 \times 10^{-6} \mathrm{~m}^{3} / \mathrm{s}\right)$. AR flow rate $=83 \times 10^{-6} \mathrm{~m}^{3} / \mathrm{s}$.

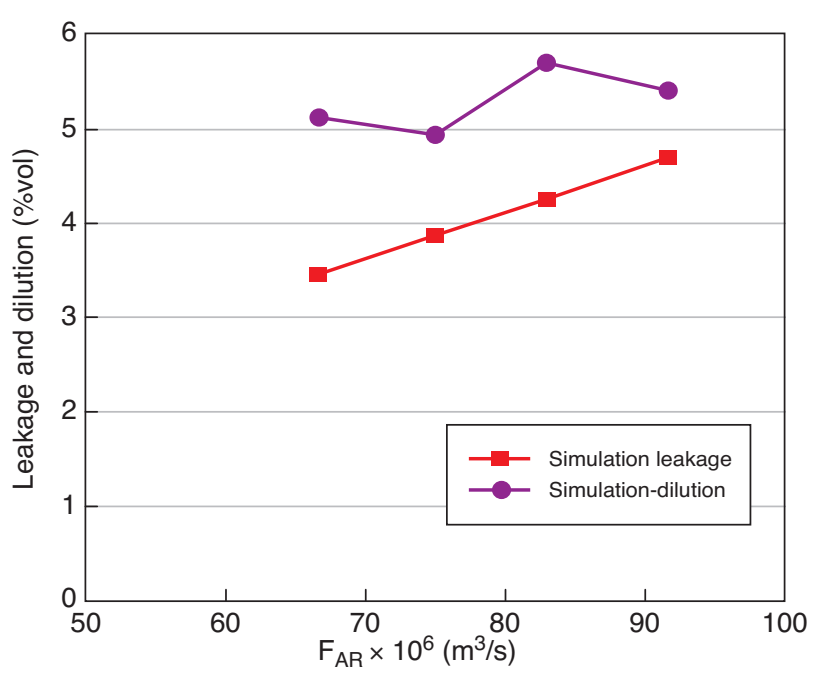

Figure 10

Variation in leakage and dilution $(\% \mathrm{vol})$ with AR flow rate $\left(66.7 \times 10^{-6}\right.$ to $\left.91.7 \times 10^{-6} \mathrm{~m}^{3} / \mathrm{s}\right)$. FR flow rate $=5.8 \times 10^{-6} \mathrm{~m}^{3} / \mathrm{s}$.

exchange between the reactors increases with an increase in the fuel flow (i.e., $F_{L}$ and $F_{D}$ increase). However the leakage, $L$, decreases primarily because of the increase in $F_{i n, F R}$. Also, an increase in the fuel flow rate increases the gas pressure on the FR side causing a decrease in the flow from the AR to FR. This results in a decrease in dilution with increasing fuel flow rate. Figure 10 shows this variation in leakage and dilution with air flow. In general, both leakage and dilution increase with an increasing air flow. The increase in leakage is primarily because of higher gas pressure in the FR side causing higher gas, as well as solids, flow through the slot.

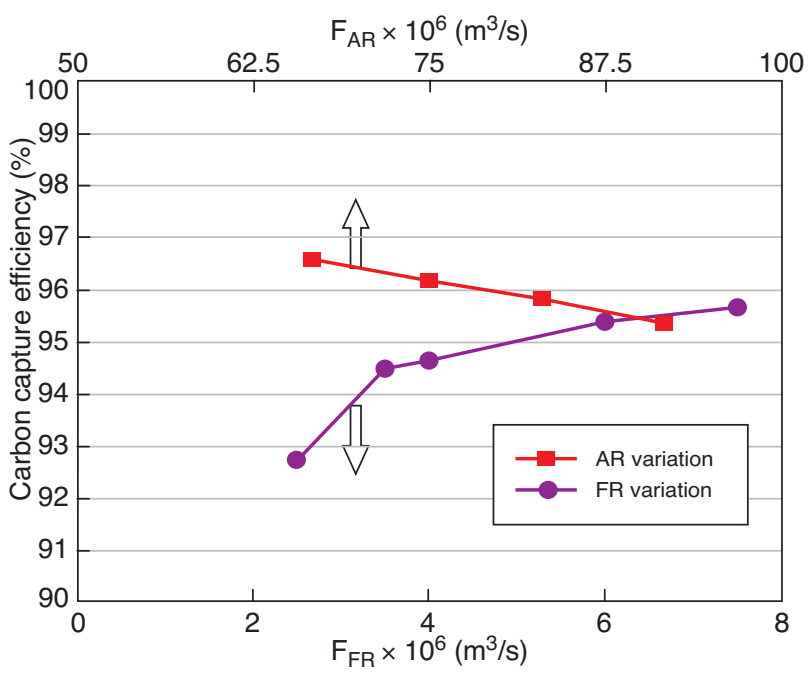

Figure 11

Variation in carbon capture efficiency (\%) with FR flow rate $\left(2.5 \times 10^{-6}\right.$ to $7.5 \times 10^{-6} \mathrm{~m}^{3} / \mathrm{s}$, bottom scale $)$ and AR flow rate $\left(66.7 \times 10^{-6}\right.$ to $91.7 \times 10^{-6} \mathrm{~m}^{3} / \mathrm{s}$, top scale $)$.

The increase in dilution is primarily because of the increased amount of gas being dragged from the AR to the FR through the downcomer due to a higher solids flow rate. The trends observed in the simulations are similar to those observed by Johansson et al. (2006) in experiments on the same system but with a different type of solid particle and different solids inventory.

Figure 11 shows the variation in the computed carbon capture efficiency with change in the fuel flow rate and air flow rate. The carbon capture efficiency is defined as:

$\eta_{\mathrm{CC}}=\frac{\mathrm{CO}_{2} \text { flow rate at exit of } \mathrm{AR}}{\mathrm{CO}_{2} \text { flow rate at exit of } \mathrm{AR}+\mathrm{CO}_{2} \text { flow rate at exit of FR }}$

High efficiency, in excess of $90 \%$, is predicted by the simulations. There is a slight increase in $\eta_{\mathrm{CC}}$ with an increase in the fuel flow rate. This is primarily because the amount of $\mathrm{CH}_{4}$ and $\mathrm{CO}_{2}$ leaking into the AR increases only marginally while the total $\mathrm{CO}_{2}$ outflow in the FR (as well as inlet $\mathrm{CH}_{4}$ flow rates) increases by more than a factor of 3 . Also, $\eta_{\mathrm{CC}}$ decreases slightly with an increase in the AR flow rate (Fig. 11), because an increase in the AR flow rate causes a higher gas pressure on the FR.

\section{CONCLUSIONS}

A CFD simulation model for simulating a complete chemical looping combustion system has been developed. The solid particles have been modeled as a continuum fluid. Chemical kinetic models have been assembled for the reactions of the 
manganese oxide carrier with the fuel gases as well as air. The CFD model was used to simulate the experiments of Abad et al., 2006. The model was able to predict the outlet concentrations of $\mathrm{CO}_{2}$ and $\mathrm{CH}_{4}$. The reactor performance at different operating temperatures was captured in a reasonable manner. It was found that the circulation of solids between the reactors is controlled by the frictional flow in the downcomer of the reactor and, hence, predicting the correct amount of frictional energy dissipation was critical in obtaining reasonable agreement between simulation and experiment. The performance of the reactor at different FR and AR flow rates was also predicted accurately. The gas leakage and dilution predictions were within the observed variance reported by Abad et al. (2006). The solid mass distribution between the AR and FR was predicted accurately. Also the outlet concentrations of flue gases, including methane, could be accurately predicted for a range of operating conditions.

\section{ACKNOWLEDGMENTS}

The authors gratefully acknowledge the financial support of the U.S. Department of Energy, Carbon Sequestration and Gasification Programs, administered at the National Energy Technology Laboratory. KM was provided support through RDS contract DE-AC26-04NT41817.

\section{REFERENCES}

Abad A., Mattisson T., Lyngfelt A., Rydén M. (2006) Chemicallooping combustion in a $300 \mathrm{~W}$ continuously operating reactor system using a manganese-based oxygen carrier, Fuel 85, 1174-1185.

Adanez J., de Diego L.F., Garcia-Labiano F., Gayan P., Abad A., Palacios J.M. (2004) Selection of Oxygen Carriers for ChemicalLooping Combustion, Energ. Fuel. 18, 371-377.

Ansys-Fluent (2006) I. Users Manual Version 6.3, Lebanon, New Hampshire.

Chandrasekaran B.K., van der Lee L., Hulme I., Kantzas A. (2005) A Simulation and Experimental Study of the Hydrodynamics of a Bubbling Fluidized Bed of Linear Low Density Polyethylene Using Bubble Properties and Pressure Fluctuations, Macromol. Mater. Eng. 290, 592-609.

Collins R. (1965) An extension of Davidson's theory of bubbles in fluidized beds, Chem. Eng. Sci. 20,747-755.

de Souza-Santos M.L. (2004) Solid Fuels Combustion and Gasification: Modeling, Simulation, and Equipment Operation, Marcel Dekker Inc., New York.

Gidaspow D. (1994) Multiphase Flow and Fluidization Continuum and Kinetic Theory Descriptions, Academic Press, San Diego.
Guenther C., Syamlal M., Shadle L.J., Ludlow C. (2002) A Numerical Investigation of an Industrial Scale Gas-Solids CFB, 7th International Conference on Circulating Fluidized Beds, Niagara Falls, Canada, May 5-8.

Hulme I., Clavelle E., van der Lee L., Kantzas A. (2005) CFD modeling and validation of bubble properties for a bubbling fluidized bed, Ind. Eng. Chem. Res. 44, 4254-4266.

Johansson E., Mattisson T., Lyngfelt A., Thunman H. (2006) A $300 \mathrm{~W}$ laboratory reactor system for Chemical-Looping Combustion with particle circulation, Fuel 85, 1428-1438.

Johnson P.C., Jackson R. (1987) Frictional-collisional constitutive relations for granular materials, with application to plane shearing, J. Fluid Mech. 176, 67-93.

Kronberger B., Johansson E., Löffler G., Mattisson T., Lyngfelt A., Hofbauer H. (2004) A two-compartment fluidized bed reactor for $\mathrm{CO}_{2}$ capture by Chemical-Looping Combustion, Chem. Eng. Technol.27, 1318-1326.

Langroudi M.K., Turek S., Ouazzi A., Tardos G.I. (2010a) An investigation of frictional and collisional powder flows using a unified constitutive equation, Powder Technol. 197, 91-101.

Langroudi M.K., Turek S., Ouazzi A., Tardos G.I. (2010b) Corrigendum to "An investigation of frictional and collisional powder flows using a unified constitutive equation" [Powder Technol. 197, 91-101], Powder Technol. 198, 314.

Lyngfelt A., Leckner B., Mattisson T. (2001) A fluidized-bed combustion process with inherent $\mathrm{CO}_{2}$ separation; application of Chemical-Looping Combustion, Chem. Eng. Sci. 56, 3101-3113.

Mahalatkar K., Huckaby E.D., Kuhlman J., O’Brien T.J. (2010) Computational fluid dynamics simulations of a chemical looping fuel reactor using solid fuel, Chem. Eng. Sci., under review.

Mao D., Edwards J.R., Kuznetsov A.V., Srivastava R.K. (2004) Three-dimensional numerical simulation of a circulating fluidized bed reactor for multi-pollutant control, Chem. Eng. Sci. 59, 4279-4289.

Mathiesen V., Solberg T., Hjertager B.H. (2000) An experimental and computational study of multiphase flow behavior in a circulating fluidized bed, Int. J. Multiphas. Flow 26, 387-419.

Mattisson T., Abanades J.C., Lyngfelt A., Abad A., Johansson M., Adanez J., Garcia-Labiano F., de Diego L.F., Gayan P., Kronberger B., Hofbauer H., Luisser M., Palacios J.M., Alvares D., Grasa G., Oakey J., Arias B., Orjala M., Heiskanen V.-P. (2005) Capture of $\mathrm{CO}_{2}$ in Coal Combustion (CCCC), Final Report, ECSC Coal RTD Programme, Contract No. 7220-PR-125, Chalmers University of Technology, Göteborg.

O'Brien T.J., Syamlal M. (1993) Particle Cluster Effects in the Numerical Simulation of a Circulating Fluidized Bed, 4th International Conference on Circulating Fluidized Beds, Somerset, Pennsylvania, August 1-5.

Samuelsberg A., Hjertager B.H. (1996) An experimental and numerical study of flow patterns in a circulating fluidized bed reactor, Int. J. Multiphas. Flow 22, 575-591.

Son S.R., Kim S.D. (2006) Chemical-Looping Combustion with $\mathrm{NiO}$ and $\mathrm{Fe}_{2} \mathrm{O}_{3}$ in a thermobalance and circulating fluidized bed reactor with double loops, Ind. Eng. Chem. Res. 45, 2689-2696.

Final manuscript received in December 2010 Published online in April 2011 or distributed for profit or commercial advantage and that copies bear this notice and the full citation on the first page. Copyrights for components of this work owned by others than IFP Energies nouvelles must be honored. Abstracting with credit is permitted. To copy otherwise, to republish, to post on servers, or to redistribute to lists, requires prior specific permission and/or a fee: Request permission from Information Mission, IFP Energies nouvelles, fax. +33147527096 , or revueogst@ifpen.fr. 